\title{
Widespread microbial invasion of the chorioamniotic membranes is a consequence and not a cause of intra-amniotic infection
}

\author{
Mi Jeong Kim ${ }^{1,2}$, Roberto Romero ${ }^{1,2,3,4}$, Maria Teresa Gervasi ${ }^{5}$, Jung-Sun Kim 1,2,6, Wonsuk Yoo ${ }^{7}$, Deug-Chan Lee ${ }^{1,2}$, \\ Pooja Mittal ${ }^{1,2,4}$, Offer Erez ${ }^{1,2,4}$, Juan Pedro Kusanovic ${ }^{1,2,4}$, Sonia S Hassan ${ }^{1,2,4}$ and Chong Jai Kim ${ }^{1,2,6}$
}

Acute chorioamnionitis is a response to amniotic fluid (AF) infection. However, it remains unclear whether substantial bacterial propagation in the chorioamniotic membranes (CAMs) precedes microbial invasion of the amniotic cavity (MIAC), which is inconsistent with characteristic 'amniotropic neutrophil migration' in acute chorioamnionitis. This study was performed to determine whether CAMs have widespread bacterial infection during MIAC and whether bacteria normally colonize CAMs. AF pellets and CAMs from the following groups were studied: group 1, patients with positive $(n=18)$ or negative $(n=22)$ AF cultures; group 2, patients with or without acute chorioamnionitis in which the amnion and chorion were studied separately $(n=60)$; and group 3, patients at term who underwent a cesarean delivery $(n=30)$. SYTO 9/propidium iodide fluorescent staining and fluorescent in situ hybridization for 16S rRNA were performed. Realtime quantitative PCR for $16 \mathrm{~S}$ rDNA and PCR for genital mycoplasmas were also conducted. Bacteria were more frequently detected in AF than in CAMs of patients with positive AF culture (100 vs. 33\%; $P<0.0001)$. Bacteria were detected more frequently in CAMs as the severity of chorioamnionitis increased $(P<0.01)$. The median 16S rRNA gene copy number in the amnion was significantly greater than in the chorion (group 2; $P<0.0001$ ). Bacteria were not detected in CAMs or AF in women at term before labor (group 3). A fraction of patients with chorioamnionitis or MIAC did not have bacteria in CAMs. Collectively, the findings herein indicate that MIAC does not follow widespread infection of CAMs, but precedes it. We propose a model of MIAC: the initial stage is intra-amniotic bacterial invasion through a discrete region of the CAMs, followed by intra-amniotic proliferation, and bacterial invasion of CAMs primarily extends from the amniotic fluid. This study emphasizes the importance of assessing the intra-amniotic compartment for diagnosis and treatment of preterm birth.

Laboratory Investigation (2009) 89, 924-936; doi:10.1038/labinvest.2009.49; published online 8 June 2009

KEYWORDS: 16S rRNA; amniotic fluid; chorioamnionitis; fluorescent in situ hybridization; intra-amniotic infection; polymerase chain reaction

Microbial invasion of the amniotic cavity (MIAC) is defined as a 'positive amniotic fluid culture for bacteria or genital mycoplasmas.' Genital mycoplasmas (and in particular, Ureaplasma urealyticum), Streptococcus agalactiae, as well as other Gram-positive and -negative aerobic and anaerobic organisms have been implicated in MIAC which, in turn, elicits a robust intra-amniotic inflammatory response and acute histologic chorioamnionitis. ${ }^{2-4}$ Acute chorioamnionitis is the most frequent pathologic lesion of the placenta in patients who had a spontaneous preterm delivery with intact or ruptured membranes. ${ }^{5}$ This is a major health-care issue because premature birth costs billions of dollars per year in the United States alone, ${ }^{6}$ and is the leading cause of perinatal morbidity and mortality worldwide, as well as the leading identifiable cause of cerebral palsy and neurologic handicap. ${ }^{7,8}$

\footnotetext{
${ }^{1}$ Perinatology Research Branch, NICHD/NIH/DHHS, Bethesda, MD, USA; ${ }^{2}$ Perinatology Research Branch, NICHD/NIH/DHHS, Detroit, MI, USA; ${ }^{3}$ Center for Molecular Medicine and Genetics, Wayne State University, Detroit, MI, USA; ${ }^{4}$ Department of Obstetrics and Gynecology, Wayne State University School of Medicine, Detroit, MI, USA; ${ }^{5}$ UO Ostetricia e Ginecologia, Azienda Ospedale/Universita, Padova, Italy; ${ }^{6}$ Department of Pathology, Wayne State University School of Medicine, Detroit, MI, USA and ${ }^{7}$ Translational Research and Clinical Epidemiology, Department of Internal Medicine, Wayne State University School of Medicine, Detroit, MI, USA

Correspondence: Dr CJ Kim, MD, PhD, Department of Pathology, Wayne State University School of Medicine, 4 Brush North, Room 4620, Hutzel Women's Hospital, 3990 John R, Detroit, Ml 48201, USA. E-mail: cjkim@med.wayne.edu or Dr R Romero, MD, Perinatology Research Branch, 4 Brush, Hutzel Women's Hospital, 3990 John R, Detroit, MI 48201, USA. E-mail: prbchiefstaff@med.wayne.edu
}

Received 18 March 2009; revised 18 April 2009; accepted 29 April 2009 
Intrauterine infection/inflammation is the only mechanism of disease for spontaneous preterm labor/delivery for which a clear causal relationship has been established. ${ }^{9-11}$ The most common pathway of intra-amniotic infection is ascending intrauterine infection from the lower genital tract, which leads to MIAC. As a consequence, the organisms frequently found in the amniotic cavity are those normally present in the lower genital tract, and are capable of crossing intact membranes. ${ }^{12}$ The traditional paradigm illustrates that microorganisms from the lower genital tract traverse the endocervical canal, gain access to the decidua, invade the chorioamnion, and then cross intact membranes into the amniotic cavity. ${ }^{9,13,14}$ This pathway is considered to have either a stage of localized decidual infection close to the uterine cervix ${ }^{15-18}$ or a stage in which there is widespread propagation of bacteria within the chorioamniotic membranes. ${ }^{9,13,14}$ Indeed, a recent study using fluorescent in situ hybridization (FISH) with an oligonucleotide probe to eubacterial $16 \mathrm{~S}$ rRNA demonstrated bacteria in a large proportion of chorioamniotic membranes of placentas with both term and preterm deliveries, even in the absence of histologic chorioamnionitis. A major conclusion of that study is that bacteria are present in the chorioamniotic membranes of a large number of patients, and that they do not elicit an inflammatory reaction. ${ }^{19}$

It is of major interest that the histopathological features of acute chorioamnionitis do not support the presence of widespread chorioamniotic/choriodecidual infection before MIAC. The inflammatory response is generally induced at or around the foci of microorganisms in other sites of the human body. However, acute chorioamnionitis is characterized by a diffuse infiltration of maternal neutrophils from the decidua towards the amniotic cavity (amniotropism), but not diffuse choriodecidual inflammation, as might be expected if the primary site of microbial invasion and propagation was extra-amniotic. Furthermore, neutrophilic infiltration of the subchorionic space of the chorionic plate, which is devoid of decidua, is a feature of the early stage of acute chorioamnionitis. ${ }^{20,21}$ In line with these histological characteristics, the current pathological classification defines acute chorioamnionitis as an inflammatory response to amniotic fluid infection, rather than microbial invasion of the chorioamniotic membranes. ${ }^{22,23}$ Understanding the pathway and topography of infection has implications for early identification and treatment. For example, eradication of microorganisms in amniotic fluid, rather than in the decidua, could be monitored by serial analysis of amniotic fluid. This would not be possible if the infectious process is in the choriodecidua or the amnion.

Molecular techniques, FISH, and PCR for bacterial ribosomal RNA/DNA, are being used frequently for the analysis of clinical samples in addition to or independently of conventional cultivation methods as they provide comparable sensitivity and specificity, and faster results. ${ }^{24-26}$ These techniques are particularly useful when causative micro- organisms are resistant to cultivation or in retrospective studies of samples in which microorganisms are no longer viable. ${ }^{10,27-29}$ This study was designed to compare the frequency of bacterial infection between the amniotic cavity and the chorioamniotic membranes during MIAC and to determine if bacteria normally colonize the intrauterine compartment during pregnancy. To address these questions, the presence, extent, and distribution of bacteria in human amniotic fluid and in the chorioamniotic membranes obtained from women presenting with various obstetrical conditions were analyzed.

\section{MATERIALS AND METHODS Tissue Samples}

Chorioamniotic membranes and amniotic fluid samples were obtained from three different groups of patients: group 1 $(n=40)$, patients with positive or negative amniotic fluid cultures; group $2(n=60)$, patients without or with histologic chorioamnionitis, where amnion and chorion were separately procured; and group $3(n=30)$, patients at term who underwent a cesarean delivery. The materials were retrieved from the bank of biological specimens held at the Perinatology Research Branch, Eunice Kennedy Shriver National Institute of Child Health and Human Development. The samples were snap-frozen and kept at $-80^{\circ} \mathrm{C}$ until analysis. Each patient provided written informed consent for the collection and use of samples for research purposes under the protocols approved by the Institutional Review Boards of all participating institutions.

\section{Fluorescent Staining for Bacteria}

Amniotic fluid pellets were obtained by centrifugation of amniotic fluid samples at $6000 \mathrm{~g}$ at $4^{\circ} \mathrm{C}$ for $10 \mathrm{~min}$. Ten microliters of the suspended amniotic fluid pellets were applied to glass slides and air dried. For analysis of the chorioamniotic membranes, $5-\mu \mathrm{m}$-thick frozen sections were used. The samples were stained using a LIVE/DEAD BacLight Bacterial Viability Kit containing SYTO 9 and propidium iodide (Invitrogen, Carlsbad, CA, USA). The stained slides were observed using a TCS-SP5 Leica confocal microscope.

\section{Fluorescent In Situ Hybridization (FISH)}

FISH was done using an eubacterial probe EUB338 (5'-GCTGCCTCCCGTAGGAGT- $3^{\prime}$ ) and a nonsense probe NSEUB338 (5'-ACTCCTACGGGAGGCAGC- $\left.3^{\prime}\right)$ labeled with $6^{\prime}$-carboxyfluorescein $\mathrm{Cy} 3$ at the $5^{\prime}$ end (Integrated DNA Technologies, Coralville, IA, USA). ${ }^{30}$ The slides were fixed briefly with $4 \%$ paraformaldehyde at $4^{\circ} \mathrm{C}$ for $30 \mathrm{~min}$ and dehydrated in graded ethanol. The slides were hybridized overnight at $46^{\circ} \mathrm{C}$ with hybridization buffer $[0.9 \mathrm{M} \mathrm{NaCl}$, $20 \mathrm{mM}$ Tris- $\mathrm{HCl}(\mathrm{pH} 8.0), 0.01 \%$ sodium dodecyl sulfate, $50 \%$ formamide] containing $50 \mathrm{ng} / \mu \mathrm{l}$ of EUB338 or NSEUB338. After hybridization, the slides were washed with hybridization buffer. Positive controls for Gram-positive and Gram-negative bacteria were Streptococcus sanguinis (ATCC 10556, Manassas, VA, USA) and Escherichia coli (ATCC 
11775), respectively. The slides were mounted using antifading aqueous mounting medium (DAKO, Carpinteria, CA, USA) containing $4^{\prime}$, 6'-diamidino-2-phenylindole $(1 \mathrm{ng} / \mathrm{ml})$.

\section{Real-Time Quantitative PCR (qPCR)}

Genomic DNA was isolated from the amniotic fluid pellets or snap-frozen chorioamniotic membranes using a DNeasy blood \& tissue kit (QIAGEN GmbH, Hilden, Germany) according to the manufacturer's instructions and used for subsequent qPCR. Universal forward primer, 5'-TCCTACG GGAGGCAGCAGT-3', reverse primer, 5'-GGACTACCAGG GTATCTAATCCTGTT- $3^{\prime}$, and the probe, 6-FAM-5'-CGTAT TACCGCGGCTGCTGGCAC-3'-TAMRA were used for detection of bacteria (Integrated DNA Technologies). ${ }^{31}$ The probe and primer sets were based on identical regions within $16 \mathrm{~S}$ rDNA following the alignment of sequences from most groups of bacteria. ${ }^{32}$ The universal primers did not amplify human DNA (data not shown). Common primers for two biovars (UU-1524R: 5' ${ }^{\prime}$-TTCCTGTTGCCCCTCAGTCT-3' and UU-1613F: $5^{\prime}$-AAGGTCAAGGTATGGAAGATCCAA- $3^{\prime}$ ) and two biovar-specific probes (UU-parvo: 6-FAM-5'-TCCA CAAGCTCCAGCAGCAATTTG-TAMRA-3' and UU-T960: VIC-5'-ACCACAAGCACCTGCTACGATTTGTTC-TAMRA-3') were used for the detection of Ureaplasma urealyticum (U. urealyticum). ${ }^{33}$ To detect Mycoplasma hominis ( $M$. hominis), forward primer, 5'-GGAAGATATGTAACAAAAGA AGGTGCTG- $3^{\prime}$, reverse primer, $5^{\prime}$-TTTATCTTCTGGCGTAA TGATATCTTCG- $3^{\prime}$, and the probe, 6-FAM-5'-AGCA GGTG CTAAAAAGGTGTTTATTACTGCTCC-TAMRA- ${ }^{\prime}$, were designed based on conserved DNA sequence within the M. hominis gap gene. ${ }^{34}$

For the absolute quantification of $16 \mathrm{~S}$ rRNA gene copies, a $16 \mathrm{~S}$ rDNA fragment was generated by PCR using the universal bacterial primer set described above. The amplified fragment was cloned into pGEM-T Easy vector (Promega Corporation, Madison, WI, USA) and transformed into Escherichia coli JM 109 (Promega). Purified plasmid DNA was used as the standard. PCR was performed in a total volume of $20 \mu \mathrm{l}$ containing $50 \mathrm{ng}$ of template DNA, $500 \mathrm{nM}$ universal primers and probes, and TaqMan Universal PCR Master Mix (Applied Biosystems, Foster City, CA, USA). A 7500 Fast Real-time PCR System (Applied Biosystems) was used for PCR. Reactions were done in triplicate and 16S rRNA gene copy numbers were calculated based on a standard curve obtained from PCR using the amount of $16 \mathrm{~S}$ rDNA plasmid ranging from $3 \times 10$ to $3 \times 10^{6}$ copies. For negative control, template DNA was replaced with an equal volume of distilled water obtained after the elution stage of a mock DNA extraction procedure. For real-time PCR of $U$. urealyticum and $M$. hominis, the primers and the probes were used at the concentration of $1 \mu \mathrm{M}$ and $250 \mathrm{nM}$, respectively. The reaction conditions were composed of $95^{\circ} \mathrm{C}$ for $20 \mathrm{~s}, 40$ cycles of $95^{\circ} \mathrm{C}$ for $3 \mathrm{~s}$, and $60^{\circ} \mathrm{C}$ for $30 \mathrm{~s}$. The results were considered positive when the value of the threshold cycle $\left(C_{\mathrm{t}}\right)$ was 35 or less. ${ }^{33}$

\section{Statistical Analysis}

Medians and ranges were determined for continuous demographic data while proportions and their frequencies were determined for categorical data. The distributions of continuous variables were examined for skewness and normality using Kolmogorov-Smirnov tests. Fisher's exact test was used for the comparison of proportions of the cases with bacteria in the amniotic fluid and the chorioamniotic membranes. Kruskal-Wallis tests were used to compare medians among groups based on the severity of inflammation and among groups according to the results of amniotic fluid cultures. Generalized estimating equations regression models were used to evaluate significance of difference in 16S rRNA gene copy numbers between the amnion and the chorion. The model was adjusted for the severity of inflammation to determine if there was a difference in the proportion of $\mathrm{qPCR}$ $(+)$ cases between the cases without and with chorioamnionitis and if the number of $16 \mathrm{~S}$ rRNA gene copies differs with the severity of chorioamnionitis.

\section{RESULTS \\ MIAC and Colonization/Infection of Chorioamniotic Membranes: Observations in Group 1}

An initial analysis was conducted to determine if cases with proven MIAC (defined as a positive amniotic fluid culture) have bacteria in the chorioamniotic membranes. The demographic characteristics of patients in group 1, according to the presence or absence of positive amniotic fluid cultures, are summarized in Table 1. In the cases with MIAC $(n=18)$, bacteria were found in $78 \%(14 / 18)$ of the amniotic fluid pellets by either fluorescent staining or FISH (Figure 1b). However, bacteria were detected only in $22 \%(4 / 18)$ of the cases by either fluorescent staining or FISH in the chorioamniotic membranes. The cumulative results of fluorescent staining, FISH, qPCR for $16 \mathrm{~S}$ rDNA, or real-time PCR for $U$. urealyticum or $M$. hominis were positive in $100 \%(18 / 18)$ of the amniotic fluid pellets and 33\% (6/18) of the chorioamniotic membranes, respectively (Figure $1 \mathrm{a}$ and b). Sixteen out of 18 amniotic fluid culture-positive cases had variable degrees of histologic chorioamnionitis (Figure 1b), and bacteria were not detected in the chorioamniotic membranes of two cases without histologic chorioamnionitis. In cases with positive amniotic fluid cultures, bacteria were detected more frequently in amniotic fluid than in the chorioamniotic membranes (100 vs 33\%; $P<0.0001)$ (Figure 1a).

In cases without MIAC $(n=22)$, bacteria were detected using a combination of molecular microbiologic techniques in $27 \%(6 / 22)$ and $14 \%(3 / 22)$ of amniotic fluid samples and the chorioamniotic membranes, respectively (Figure 1a). Bacteria were detected by FISH and fluorescent staining in three amniotic fluid pellets (Figure 1c). qPCR for $16 \mathrm{~S}$ rDNA gave positive results in two additional amniotic fluid samples with an absolute qPCR cutoff value for a positive result of $50016 \mathrm{~S}$ rRNA gene copies/50 ng of template DNA. Among 
Table 1 The demographics of the patients in group 1

\begin{tabular}{|c|c|c|c|c|}
\hline \multirow[t]{2}{*}{ Characteristics } & \multirow[t]{2}{*}{ Total $(n=40)$} & \multicolumn{2}{|c|}{ AF culture } & \multirow[t]{2}{*}{$P$-value } \\
\hline & & Positive $(n=18)$ & Negative $(n=22)$ & \\
\hline Maternal age (years) & $21(15-45)$ & $21(16-45)$ & $21(15-41)$ & 0.827 \\
\hline Gestational age (weeks) & $38(23-42)$ & $38(23-42)$ & $39(24-40)$ & 0.540 \\
\hline \multicolumn{5}{|l|}{ Delivery mode } \\
\hline Vaginal delivery & $27 / 40(68 \%)$ & $12 / 18(67 \%)$ & 15/22 (68\%) & 0.701 \\
\hline Cesarean delivery & $13 / 40(33 \%)$ & 6/18 (33\%) & $7 / 22(32 \%)$ & 0.782 \\
\hline
\end{tabular}

Values were expressed in median (range) or ratio (percentage).

Culture refers to routine cultivation methods for bacteria (aerobic or anaerobic bacteria, U. urealyticum and M. hominis).

AF: amniotic fluid.

the 22 cases, five patients had histologic chorioamnionitis, among which four cases had bacteria detected by fluorescent staining, FISH, qPCR for $16 \mathrm{~S}$ rDNA or real-time PCR for $U$. urealyticum in amniotic fluid. Histologic chorioamnionitis was not present in three cases in which bacteria were detected in the amniotic fluid for two cases by fluorescent staining/ FISH or $16 \mathrm{~S}$ rDNA qPCR, and in the chorioamniotic membranes for the other case by real-time PCR for U. urealyticum. A case of histologic chorioamnionitis, in which bacteria were not detected, had meconium staining of the chorioamniotic membranes. In three cases with MIAC, bacteria were not observed, and in three cases without MIAC, bacteria were observed in the amniotic fluid or the chorioamniotic membranes using FISH or fluorescent staining (Figure 1d). Using PCR (qPCR for $16 \mathrm{~S}$ rDNA, or real-time PCR for $U$. urealyticum or $M$. hominis), bacteria were detected in the amniotic fluid or the chorioamniotic membranes for four cases without MIAC and for all cases with MIAC.

When bacteria were detected in the amniotic fluid pellets or chorioamniotic membranes by FISH or fluorescent staining, they were far more readily found in the amniotic fluid than in the chorioamniotic membranes. The bacterial distribution pattern in the chorioamniotic membranes was not diffuse but discrete. The destruction of amnion epithelial cells by bacterial invasion was evident despite bacteria being absent or rarely detected in the chorioamniotic connective tissue layer, indicating that the invasion began from the amniotic cavity. Two representative cases with positive amniotic fluid culture are shown in Figure 2.

To extend the study, we included one unique case of a twin gestation (Figure $3 \mathrm{a}-\mathrm{c}$ ), in which only one amniotic cavity had bacteria, and a case of quadruplets (Figure 3d), in which one of the four amniotic cavities had detectable bacteria. In each case, histologic chorioamnionitis was confined to the membranes with MIAC. Fluorescent staining revealed numerous bacteria in the amniotic fluid pellets of both cases with MIAC (Figure $3 \mathrm{~b}$ and c). Clusters of bacteria infiltrating and densely packing the amnion epithelial cells were observed and demonstrated obvious cytopathic changes. In contrast, bacteria were relatively rare in the chorion and decidua as was observed in the large number of singleton pregnancies, which represent most cases in this study (Figure $3 c$ and $d)$.

\section{Bacterial Colonization/Infection of Chorioamniotic Membranes in Histologic Chorioamnionitis: Observations in Group 2}

Further analysis was performed in a group of extra-placental chorioamniotic membranes without and with histologic chorioamnionitis. In this part of the study, the chorioamniotic membranes were separated by blunt dissection so that the amnion and chorion could be studied separately. The demographic characteristics of the patients are summarized in Table 2. The severity of maternal inflammatory response of histologic acute chorioamnionitis was graded according to the criteria previously proposed. ${ }^{22}$ The analysis was conducted to evaluate the prevalence and abundance of bacteria according to the severity of histologic chorioamnionitis, and also to determine if there was a difference in bacterial abundance between the inner layer (amnion) and the outer layer (chorion) of the chorioamniotic membranes. The proportion of membranes (amnion or chorion) with detectable bacteria was $33,40,60$, and $87 \%$ of the cases as a function of the severity of histologic chorioamnionitis (stage 

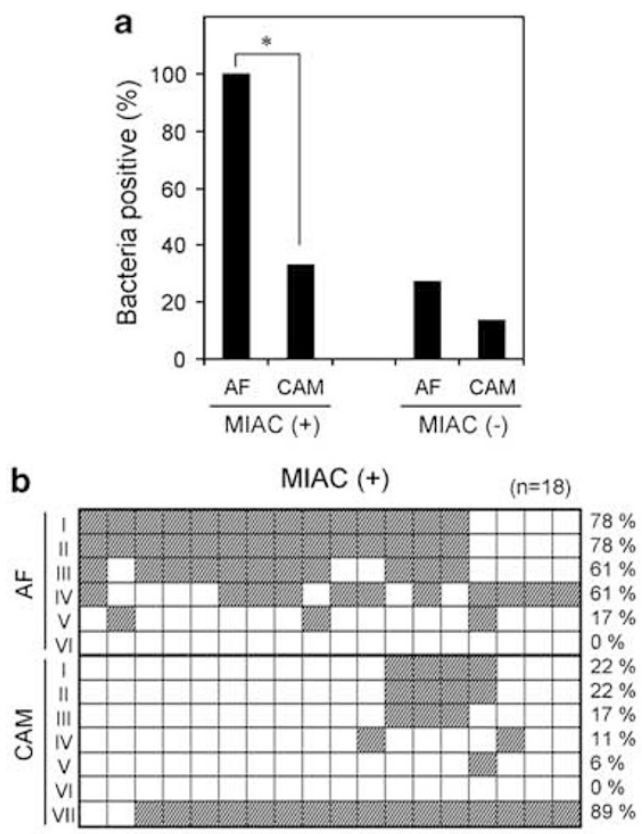

C

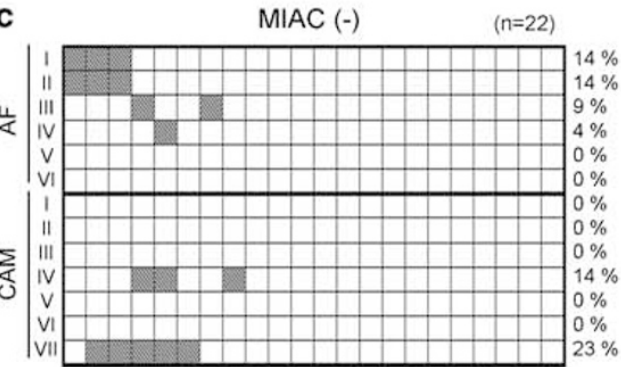

I. Fluorescent staining

II. 16S rRNA FISH

III. 16S rDNA qPCR

IV. U. urealyticum (parvo) PCR

V. U. urealyticum (T960) PCR

VI. M. hominis PCR

VII. Acute chorioamnionitis

d

Group $1(n=40)$
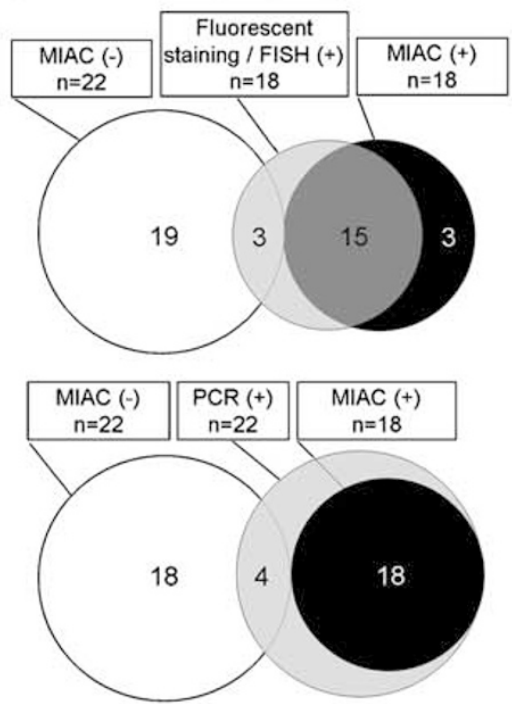

$0,1,2$, and 3-stage 0 represents the absence of chorioamnionitis), when the results of fluorescent staining, $16 \mathrm{~S}$ rDNA qPCR, and real-time PCR for $U$. urealyticum or $M$. hominis were all combined (Figure 4a). There was a correlation between the severity of histologic chorioamnionitis and the presence of bacteria $(P<0.01)$.

Using fluorescent staining, bacteria were detected in $7 \%$ (1/15), $0 \%(0 / 15), 20 \%(3 / 15)$, and $7 \%(1 / 15)$ of the cases with histologic chorioamnionitis in stages $0,1,2$, and 3 , respectively (Figure $4 \mathrm{~b}$ ). qPCR analysis revealed $16 \mathrm{~S}$ rRNA gene copy numbers greater than 500/50 ng of genomic DNA either in the amnion or chorion in $27,27,33$, and $53 \%$ of the cases with histologic chorioamnionitis in stages $0,1,2$, and 3 , respectively. Real-time PCR analysis of the chorioamniotic membranes for $U$. urealyticum revealed parvo biovar in $13 \%$ (2/15), $13 \%(2 / 15), 40 \%(6 / 15)$, and $40 \%(6 / 15)$ in stages 0 , 1,2 , and 3 chorioamnionitis, respectively (Figure $4 \mathrm{~b}$ ). T960 biovar was amplified in $0 \%(0 / 15), 13 \%(2 / 15), 7 \%(1 / 15)$, and $0 \%(0 / 15)$ in stages $0,1,2$, and 3 chorioamnionitis, respectively. M. hominis was detected only in $13 \%(2 / 15)$ of the chorioamniotic membranes with stage 3 chorioamnionitis but not in other conditions. In cases without chorioamnionitis, bacteria were only detected in cases in which there was a vaginal delivery (5/7); none of the placentas delivered by cesarean section were positive for bacteria (0/8) (Figure 4b). Interestingly, 16S rRNA gene copy numbers were significantly higher in the amnion than in the chorion in all of the subgroups without and with chorioamnionitis (Figure $4 \mathrm{c}, P<0.01$ ).

\section{Amniotic Fluid and Chorioamniotic Membranes Before the Onset of Labor at Term are Sterile: Observations in Group 3}

Meticulous analysis of the SYTO 9/propidium iodide fluorescent-stained preparations of amniotic fluid pellets and the chorioamniotic membranes obtained during cesarean sections at term without $(n=20)$ and with $(n=10)$ labor did not reveal bacteria in any of the cases $(n=30)$. Unlike the

Figure 1 Comparison of group 1 cases without $(n=22)$ and with $(n=18)$ MIAC defined by positive amniotic fluid culture. (a) Proportion of the cases in which bacterial traits were demonstrated by any fluorescent staining, FISH, $16 \mathrm{~S}$ rDNA qPCR, or real-time PCR for $U$. urealyticum or $M$. hominis in the amniotic fluid and in the chorioamniotic membranes. Bacteria were more frequently detected in the amniotic fluid than in the chorioamniotic membranes for cases with MIAC $\left({ }^{*} P<0.0001\right)$. (b, c) Maps showing proportion of the cases with histologic chorioamnionitis or the cases in which bacteria were detected in amniotic fluid and chorioamniotic membranes according to assay methods employed. (d) Venn diagrams showing proportion of cases in which bacteria were detected by different techniques. White and black circles represent cases without and with MIAC. Microscopic examinations (fluorescent staining/FISH) or PCR (16S rDNA qPCR, or real-time PCR for U. urealyticum or M. hominis) are in gray circles, for which the number represents the cases positive for bacteria in the amniotic fluid or in the chorioamniotic membranes in. MIAC: microbial invasion of the amniotic cavity, AF: amniotic fluid, CAM: chorioamniotic membranes. 
a
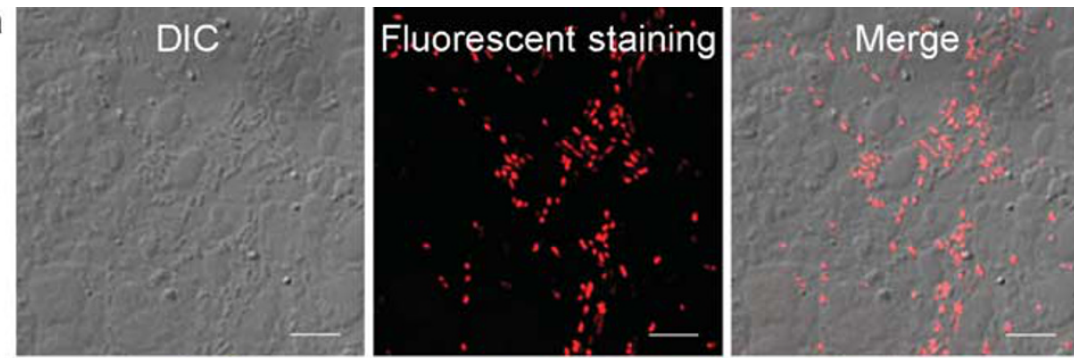

b
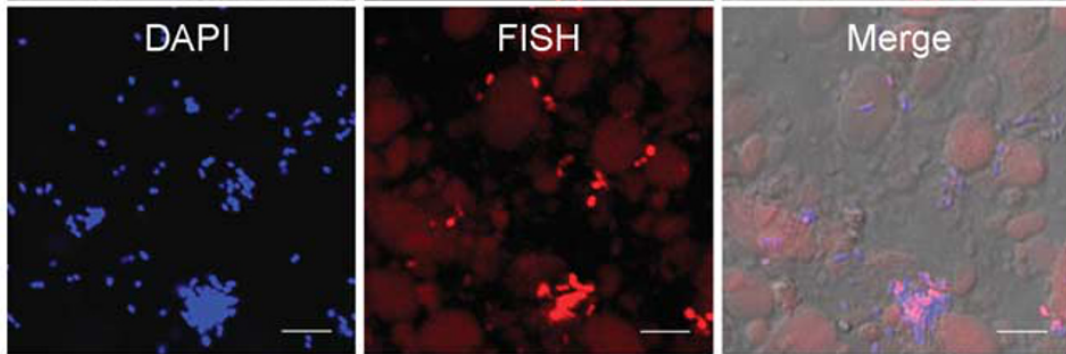

C
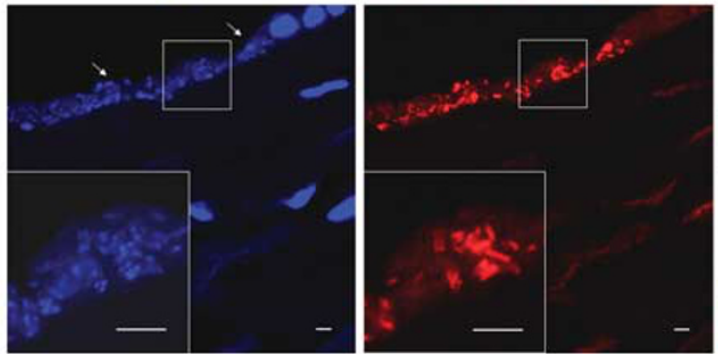

d
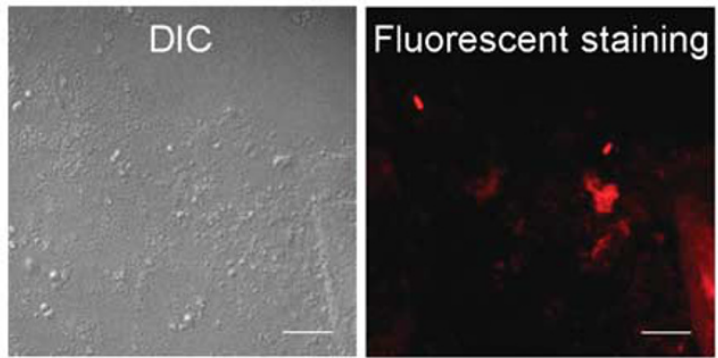

e
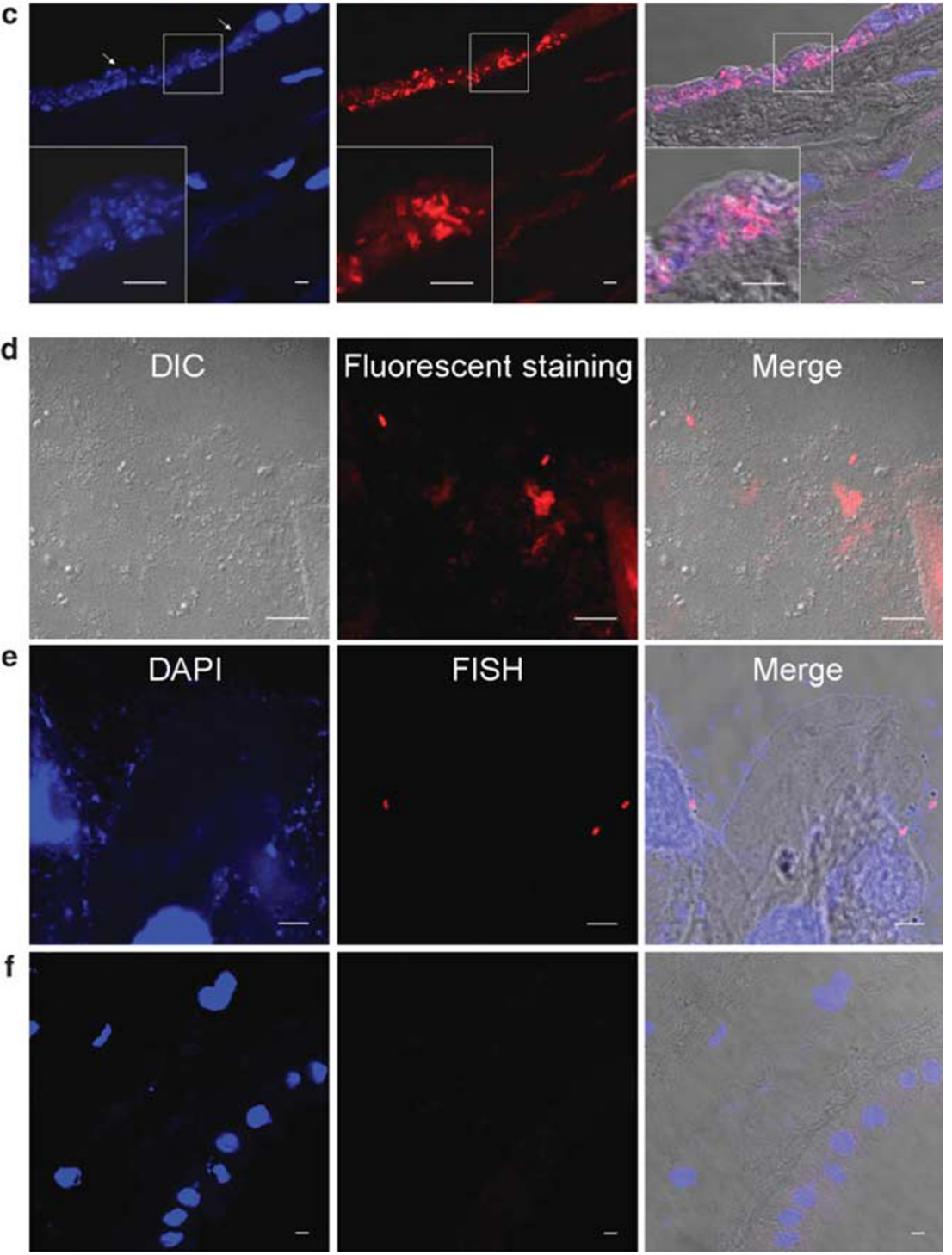

Figure 2 For caption see next page. 
cases in groups 1 and 2, all of the chorioamniotic membranes in group 3 were obtained intra-operatively to minimize the possibility of contamination during routine processing of the samples. The median gestational ages of the cases without and with labor were 39 weeks (range: 37-39 weeks) and 40 weeks (range: $38-42$ weeks), respectively.

In the cases without labor $(n=20)$, the results were consistent irrespective of methods of analysis (fluorescent staining, qPCR for $16 \mathrm{~S}$ rDNA, and real-time PCR for $U$. urealyticum). None of the samples of amniotic fluid pellets $(n=20)$ and chorioamniotic membranes $(n=20)$ was positive. The median absolute $16 \mathrm{~S}$ rRNA gene copy numbers in amniotic fluid pellets and in the chorioamniotic membranes were 0 (range: $0-50.9$ ) and 11.4 (range: $0-184.2$ ), respectively. Amniotic fluid cultures for bacteria (aerobic, anaerobic and genital mycoplasmas) were negative in all cases.

In the cases with labor $(n=10)$, the results of qPCR for $16 \mathrm{~S}$ rDNA or real-time PCR for U. urealyticum or M. hominis were positive in $20 \%(2 / 10)$ of the chorioamniotic membranes. One case was positive for $16 \mathrm{~S}$ rDNA qPCR, and the other case was positive for $U$. urealyticum (parvo). The results of $16 \mathrm{~S}$ rDNA qPCR were negative in all of the three cases in which amniotic fluid pellets were available. The pellets were available from two cases with positive results in the chorioamniotic membranes, and U. urealyticum (parvo) was also detected in the case with $U$. urealyticum (parvo) in the chorioamniotic membranes. The median absolute 16S rRNA gene copy numbers in amniotic fluid pellets and the chorioamniotic membranes were 0 (range: $0-17.4$ ) and 142.0 (range: 22.6-514.9), respectively.

\section{DISCUSSION}

Bacterial invasion into host tissues is determined by several factors, such as tissue types and virulence. For example, enteric pathogens with different invasive properties exhibit variable degrees of interaction with intestinal mucosa ranging from epithelial adherent, epithelial invasive, and mucosally invasive, or even being restricted to the lumen. ${ }^{35}$ The cau- sative microorganisms, therefore, do not necessarily need to be found in the mucosal tissue, per se, even in the cases of infection and inflammation.

Key observations in this study are that a fraction of patients with chorioamnionitis or MIAC do not have evidence of bacterial colonization and invasion of the chorioamniotic membranes, and that the amniotic cavity and the chorioamniotic membranes of pregnancies at term before the onset of labor are sterile. Imaging studies (fluorescent staining and FISH) revealed that discrete bacterial infiltration into amnion epithelial cells is a primary mode of bacterial propagation into the chorioamniotic membranes. In addition, the PCR data indicate that bacteria, when present, are more abundant in the amnion, the inner layer of the chorioamniotic membranes facing the amniotic cavity, than in the chorion. It can be argued that during a vaginal delivery, there is exposure of the amnion primarily to the birth canal, which would explain the relative bacterial abundance in the amnion. However, our conclusion is supported by the data derived from patients undergoing cesarean delivery and the localization of bacteria found in most placentas by imaging techniques.

Visual demonstration provides solid evidence that bacteria are present in clinical samples. This study is the first attempt to visualize bacteria in a large number of chorioamniotic membranes with histologic chorioamnionitis. FISH for $16 \mathrm{~S}$ rRNA is sensitive and specific, yet it takes hours to perform. ${ }^{24}$ Simple and rapid fluorescent staining using fluorescent dyes (SYTO 9/propidium iodide) was as effective as FISH in demonstrating bacteria in this study. SYTO 9 (green fluorescence) and propidium iodide (red fluorescence) differ in their spectral characteristics and ability to penetrate intact bacterial cells. ${ }^{36,37}$ A limitation of molecular bacteriologic techniques, especially PCR-based, is false-positive results due to their sensitive nature and the potential for contamination. $^{38,39}$ Fifty nanograms of template DNA were used to correspond to the amount of genomic DNA in approximately 7600 human cells. If a given bacterium has a $16 \mathrm{~S}$ rRNA gene

Figure 2 Distribution patterns of bacteria detected by either bacterial 16S rRNA FISH using an EUB338 probe or fluorescent staining. (a-c) A case showing numerous rods in amniotic fluid pellets by fluorescent staining (a) and by 16S rRNA FISH (b). (c) 16S rRNA FISH of the chorioamniotic membranes showing

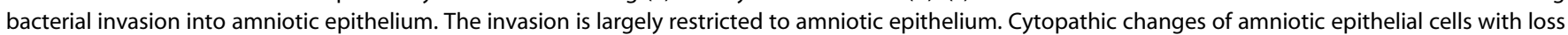
of nuclei are evident (arrows). (d-f) Another case showing scattered bacteria in amniotic fluid pellets by fluorescent staining (d) and 16S rRNA FISH (e) but not in the chorioamniotic membranes (f). Magnification $\times 630$.

Figure 3 Images of bacteria in two cases of multiple gestations demonstrated by SYTO 9/propidium iodide fluorescent staining. There were isolated MIAC and histologic chorioamnionitis restricted to only one of the fetuses in both cases. (a) Gross feature of the placenta and the amniotic fluid of a twin case. Discoloration of amniotic surface is evident in twin A, and there is stark contrast between the amniocentesis samples. (b, c) A cluster of bacteria in amniotic fluid (b) and bacterial invasion of amniotic epithelial cells (c) demonstrated by fluorescent staining. Live bacteria were stained with SYTO 9 (green fluorescence), and dead bacteria were stained with propidium iodide (red fluorescence). Note the lack of bacteria in the chorioamniotic connective tissue indicating bacterial propagation from the amniotic cavity (arrow). (d) The other case of quadruplets also showing a large number of bacteria in the amniotic fluid pellets and invasion of the amnion in the chorioamniotic membranes by those bacteria on fluorescent staining. Magnification $\times 630$. AF: amniotic fluid, CAM: chorioamniotic membranes. 
a

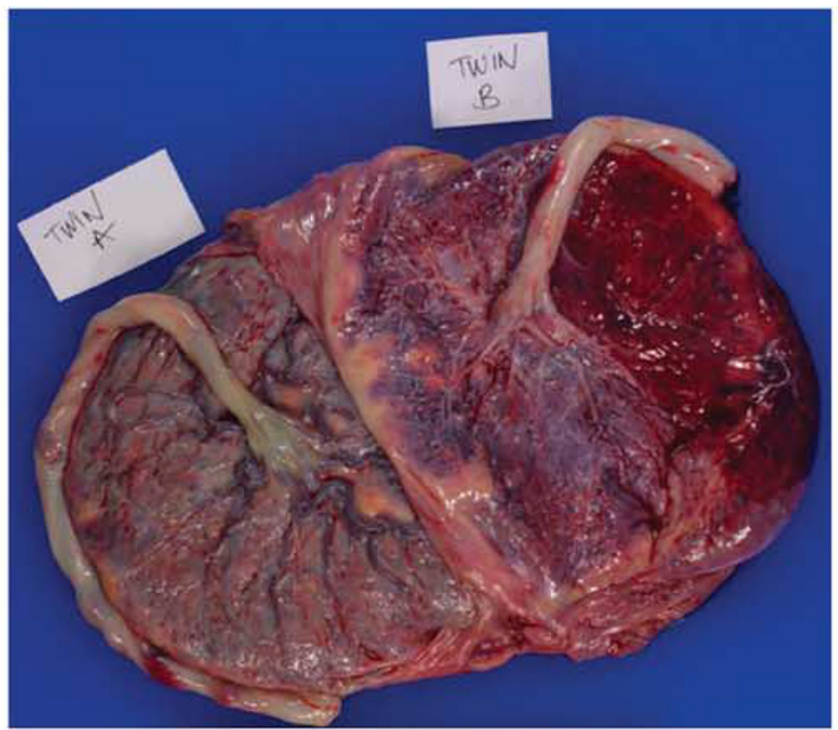

b

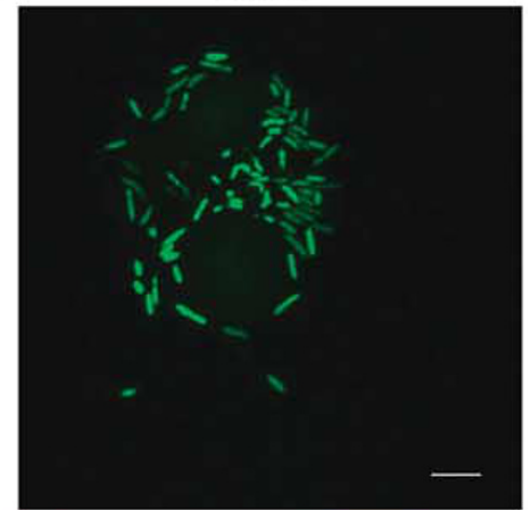

c

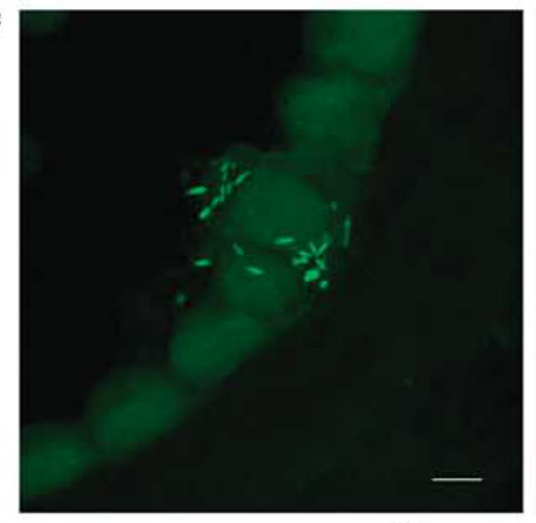

d

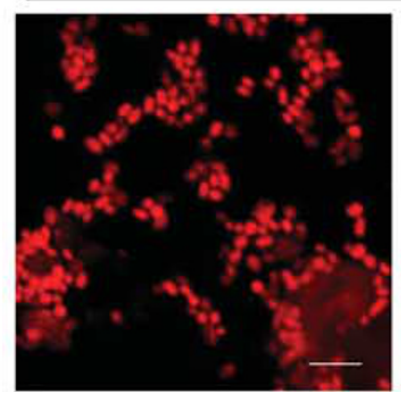

PI
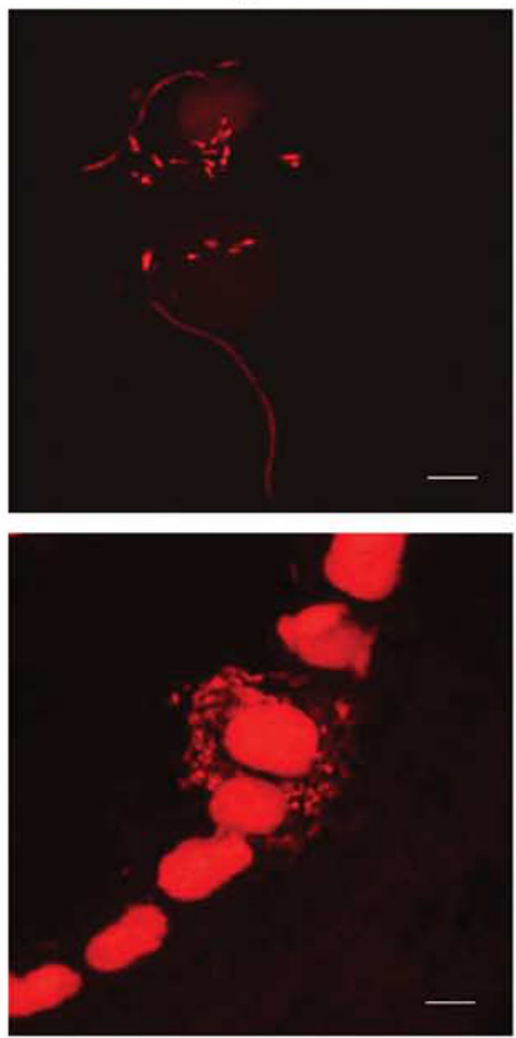

AF

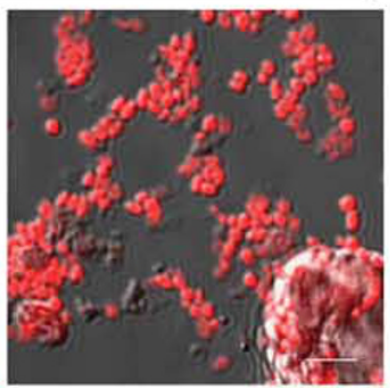

Amniotic fluid

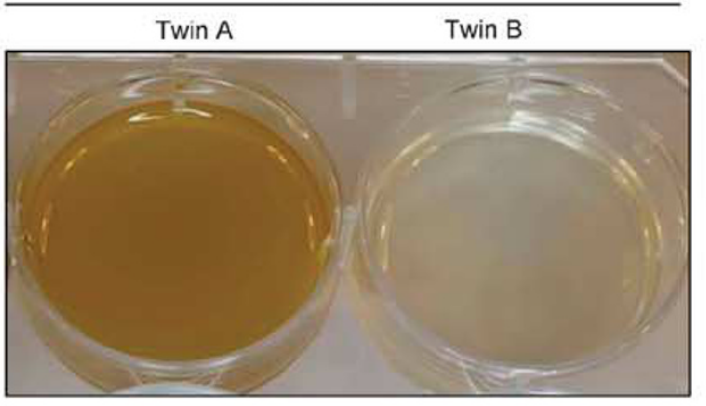

Merge
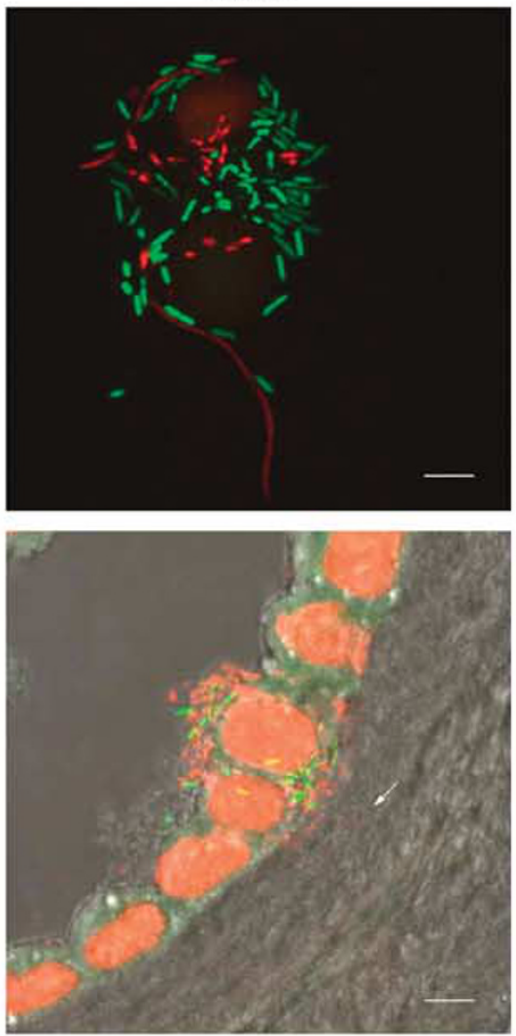

CAM

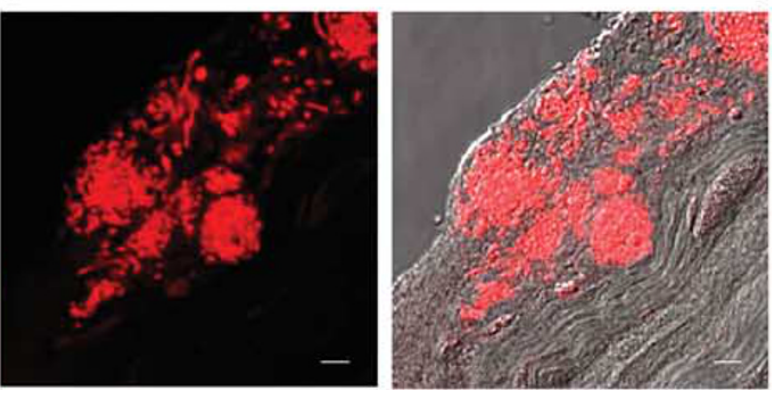


copy number of 7, like E. coli, ${ }^{40}$ the value of 500 copies would be equivalent to at least two bacteria per 100 human cells. One $\times 1000$ field covered, on average, 61 cells when we evaluated eight chorioamniotic membranes (data not shown). Thus, the $16 \mathrm{~S}$ rRNA gene copy number of 500/50 ng of template DNA was used as a cutoff value for a positive PCR. Another experiment using 50 ng of genomic DNA obtained from normal maternal $(n=5)$ and fetal $(n=5)$ peripheral blood leukocytes yielded 35.7 median copy numbers (range: 0-133.8) (data not shown). PCR is superior in identifying genital mycoplasmas, which are relatively difficult to visualize by microscopic techniques due to their polymorphic nature and small size. ${ }^{41,42}$ It is also noteworthy that qPCR using universal primers to $16 \mathrm{~S}$ rDNA could not detect $U$. urealyticum and $M$. hominis in a significant proportion of the samples in this study, and the differences in the primer sequences could be responsible for the discrepancy.

Our data indicate that the largest microbial burden is found in the amniotic cavity, and not in the chorioamniotic membranes. A substantial proportion (67\%) of cases with culture-proven MIAC in group 1 did not have detectable bacteria in the chorioamniotic membranes despite the high frequency of histologic chorioamnionitis (89\%). Although bacteria are present in an extra-amniotic location before entry into the amniotic cavity, our results indicate that diffuse bacterial invasion and proliferation of the choriodecidua and amnion is not a prerequisite for microbial entry into the amniotic cavity. Therefore, the findings in this study do not support a model for the progression of ascending infection shown in Figure $5 \mathrm{a}$, but rather mirror the pathobiological relevance of the one illustrated in Figure 5b. Bacteria present in the lower genital tract traverse the endocervical canal, cross intact or ruptured membranes through a very restricted region, and invade the amniotic cavity and proliferate in the amniotic fluid. From the amniotic cavity, microorganisms can invade the amnion, its connective tissue, and then, in severe cases, the chorion and decidua. Of special note, this model is basically similar to the one proposed by Blanc as a sequence of intra-amniotic infection after rupture of the membranes in his elegant review on the pathways of fetal and early neonatal infection. ${ }^{43}$

Intraurothelial bacterial communities have been found in women with recurrent cystitis, ${ }^{44}$ yet it is uncertain whether bacteria reside intracellularly without inducing inflammatory or pathologic responses in the chorioamniotic membranes. In gastric infections caused by Helicobacter pylori, the majority of the microorganisms are located in the epithelial cell surface or in the macrophages of the inflamed lamina propria. ${ }^{45}$ Even in the colon, which has a large burden of luminal bacteria, the epithelial cells themselves are free of microorganisms and are not in direct contact with bacteria in physiologic conditions, whereas an inflammatory response is evoked when invasion of tissue by bacteria occurs. ${ }^{46}$ Therefore, interpretation of the significance of intracellular or interstitial bacteria without an inflammatory response should be done with caution. We wish to call attention to our observation that all cases at term without labor delivered by cesarean section (group 3) did not have bacteria detectable with molecular techniques. In contrast, bacteria were detected in $33 \%$ of the cases without histologic chorioamnionitis (group 2). This is likely to be due to contamination during vaginal delivery, or even during the processing of the placenta in the laboratory. Such an interpretation would be consistent with the results of a survey of 207 normal infants. One quarter of vaginally delivered newborns had bacterial colonization of the skin after birth, whereas all of the neonates delivered by cesarean section had sterile skin. ${ }^{47}$

Seong $e t ~ a l^{48}$ recently reported the frequency of MIAC in 884 women at term with intact chorioamniotic membranes in the presence or absence of labor. MIAC was present in $1 \%$ $(6 / 775)$ of women not in labor, $3.5 \%$ (3/86) of women in

Table 2 The demographics of the patients in group 2

\begin{tabular}{|c|c|c|c|c|c|c|}
\hline \multirow[t]{2}{*}{ Characteristics } & \multirow[t]{2}{*}{ Total $(n=60)$} & \multicolumn{4}{|c|}{ Grading of acute chorioamnionitis } & \multirow[t]{2}{*}{$P$-value } \\
\hline & & None $(n=15)$ & Stage $1(n=15)$ & Stage $2(n=15)$ & Stage $3(n=15)$ & \\
\hline Maternal age (years) & $25(18-44)$ & $24(19-43)$ & $24(18-34)$ & $26(20-40)$ & $28(18-44)$ & 0.376 \\
\hline Gestational age (weeks) & $38(21-41)$ & $39(37-40)$ & $40(36-41)$ & $38(25-41)$ & $30(21-41)$ & 0.0029 \\
\hline Preterm delivery & $16 / 60(27 \%)$ & $0 / 15(0 \%)$ & $1 / 15(7 \%)$ & $3 / 15(20 \%)$ & $12 / 15(80 \%)$ & 0.004 \\
\hline \multicolumn{7}{|l|}{ Delivery mode } \\
\hline Vaginal delivery & $41 / 60(68 \%)$ & $7 / 15(47 \%)$ & $12 / 15(80 \%)$ & $10 / 15(67 \%)$ & $12 / 15(80 \%)$ & 0.662 \\
\hline Cesarean section & 19/60 (32\%) & $8 / 15(53 \%)$ & $3 / 15(20 \%)$ & $5 / 15(33 \%)$ & $3 / 15(20 \%)$ & 0.328 \\
\hline
\end{tabular}




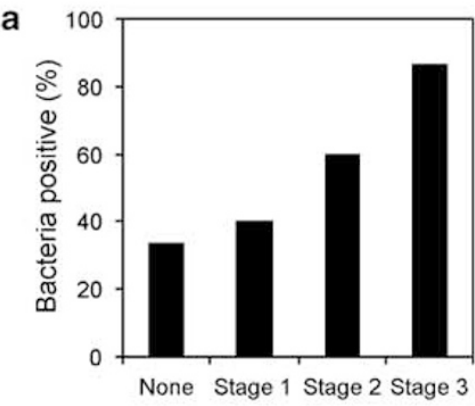

b Chorioamniotic membranes $(n=60)$

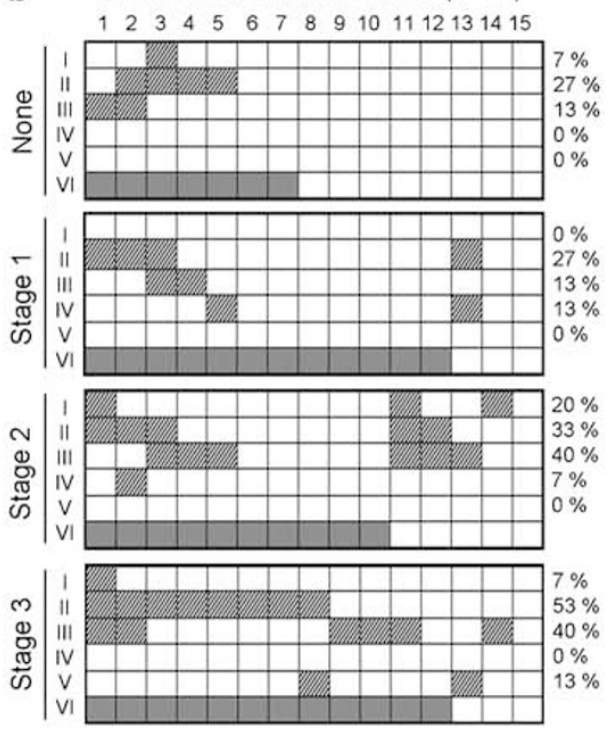

I. Fluorescent staining

II. 16S rDNA qPCR

III. U. urealyticum (parvo) PCR

IV. U. urealyticum (T960) PCR

V. M. hominis PCR

VI. Delivery mode

( $\square$ CS and $\square$ vaginal)
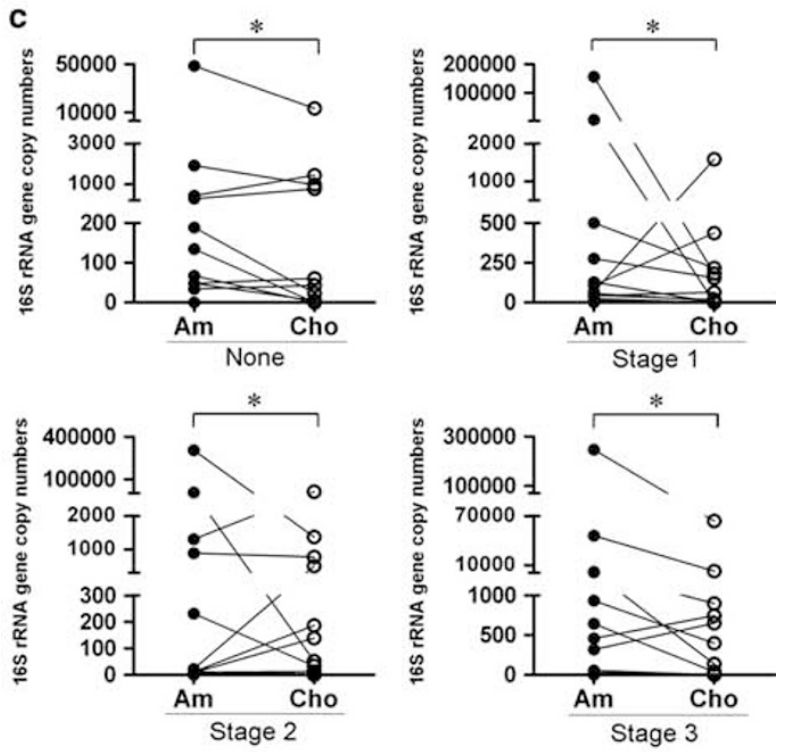

early labor, and $13 \%(3 / 23)$ of women in active labor. This data suggests that labor per se increases the likelihood of ascending microbial invasion of the amniotic cavity. Although the mechanisms for this have not been determined, two possibilities must be considered: (1) digital examinations are performed to assess cervical dilatation and effacement, and during this procedure, microbial flora from the lower genital tract may be directly carried to intact chorioamniotic membranes or the amniotic cavity when the membranes are ruptured; and (2) uterine contractions may generate a suction-like effect whereby vaginal fluid with its microbial content may be pulled into the uterine cavity. ${ }^{48,49}$

The presence of two bacteria-positive cases out of 10 women in labor at term (group 3) under this study is consistent with the explanations invoked in the previous paragraph. Key lessons from the different studies reviewed above are: (1) MIAC could happen even within a relatively short period of time during labor; (2) the initial microbial entry into the amniotic cavity could occur without diffuse microbial invasion of the choriodecidua or the amnion; and (3) functional integrity of the uterine cervix is important because the cervical mucus plug contains natural antimicrobial peptides, thus serving as an anatomical and biochemical barrier to ascending intrauterine infection. ${ }^{50}$ It is of interest that in vitro experiments demonstrate that E. coli can traverse human chorioamniotic membranes within six hours in vitro. ${ }^{51}$ The uterine cervical region and part of the chorioamniotic membranes overlying the cervix, which becomes 'the zone of altered morphology' later in pregnancy, might be the site through which the initial group of microorganisms invades the uterine cavity. ${ }^{52,53}$ Future studies about the factors governing anatomical and immunological integrity of this compartment will be necessary for a more thorough understanding of the pathobiology of the microbial invasion of the amniotic cavity.

The outcome of randomized clinical trials in which antibiotic administration to the mother to prevent spontaneous preterm birth have yielded controversial results. ${ }^{54-61}$ It is noteworthy that the negative results of these trials have been interpreted as caused by the difficulty in eradicating bacteria from either the decidua or the chorioamniotic membranes, assuming that a widespread stage exists before MIAC. The

Figure 4 Bacterial abundance and prevalence in the chorioamniotic membranes in cases with varying degrees of histologic chorioamnionitis (stage 0 (none)/1/2/3). (a) Total proportion of bacterial positive cases in the chorioamniotic membranes was significantly associated between histologic severity of chorioamnionitis (stage 0 (none)/1/2/3) and bacterial prevalence $(P<0.01)$. (b) Proportion of the cases in which bacteria were detected by fluorescent staining, qPCR for universal bacterial $16 \mathrm{~S}$ rDNA, real-time PCR for U. urealyticum two biovar (parvo and T960), or M. hominis using specific primers and probes. (c) $16 \mathrm{~S}$ rRNA gene copy numbers were evaluated by real-time quantitative PCR. $16 \mathrm{~S}$ rRNA gene copy numbers were significantly higher in the amnion (Am) than in the chorion (Cho) in all groups with chorioamnionitis (stage 0 (none)/1/2/3) $\left({ }^{*} P<0.01\right)$. 

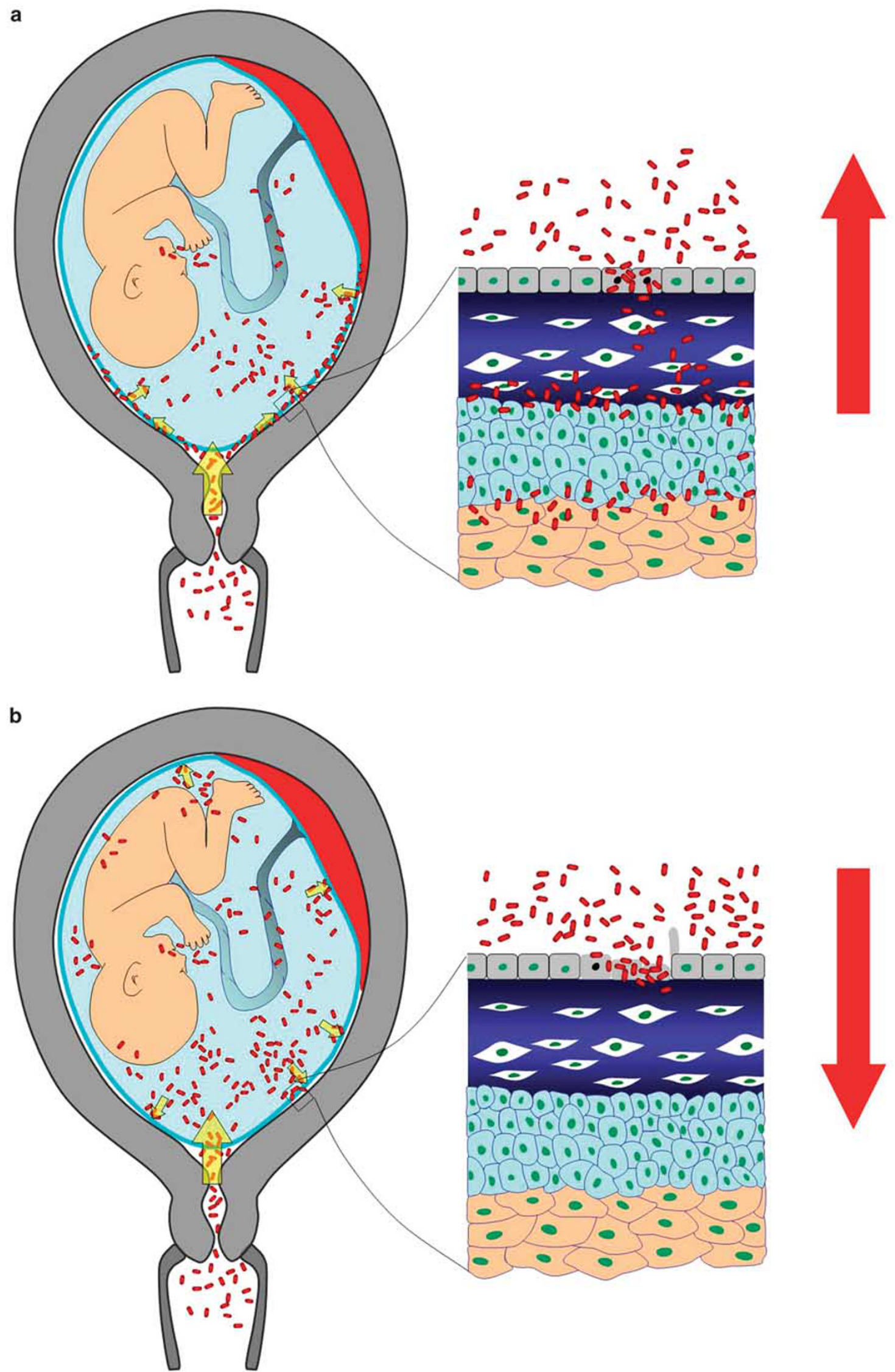
Figure 5 Two models depicting bacterial trafficking into the chorioamniotic membranes during progression of MIAC. (a) A model of MIAC, whose basic paradigm includes stages of widespread bacterial invasion along the chorioamniotic or choriodecidual planes before they enter the amniotic cavity. The findings in the present study are not consistent with model A. (b) A model of MIAC propagation supported by the findings in this study. It involves initial intra-amniotic entry of bacteria through a restricted cervical region, intra-amniotic proliferation, and subsequent adhesion and invasion of intra-amniotic bacteria into the amnion from the amniotic cavity. MIAC: microbial invasion of the amniotic cavity. Arrows indicate major direction of microbial invasion.

current study suggests that this stage does not exist frequently before MIAC, and therefore emphasizes the importance of preventing ascending microbial invasion as well as developing methods for the rapid diagnosis and effective treatment of MIAC. In conclusion, we have used molecular microbiologic techniques to identify the microorganisms in the chorioamniotic membranes, and have not been able to generate evidence in support of the presence of widespread chorioamniotic bacterial infection preceding MIAC. Our study has substantial biological and clinical implications.

\section{ACKNOWLEDGEMENT}

This research was supported (in part) by the Perinatology Research Branch, Division of Intramural Research, Eunice Kennedy Shriver National Institute of Child Health and Human Development, NIH, DHHS.

\section{DISCLOSURE/DUALITY OF INTEREST}

The authors state no conflict of interest.

1. Yoon BH, Romero R, Moon J, et al. Differences in the fetal interleukin- 6 response to microbial invasion of the amniotic cavity between term and preterm gestation. J Matern Fetal Neonatal Med 2003;13:32-38.

2. Romero $\mathrm{R}$, Yoon $\mathrm{BH}$, Mazor $\mathrm{M}$, et al. A comparative study of the diagnostic performance of amniotic fluid glucose, white blood cell count, interleukin-6, and gram stain in the detection of microbial invasion in patients with preterm premature rupture of membranes. Am J Obstet Gynecol 1993;169:839-851.

3. Coultrip LL, Lien JM, Gomez R, et al. The value of amniotic fluid interleukin- 6 determination in patients with preterm labor and intact membranes in the detection of microbial invasion of the amniotic cavity. Am J Obstet Gynecol 1994;171:901-911.

4. Yoon BH, Romero R, Park JS, et al. Microbial invasion of the amniotic cavity with Ureaplasma urealyticum is associated with a robust host response in fetal, amniotic, and maternal compartments. Am J Obstet Gynecol 1998;179:1254-1260.

5. Romero R, Espinoza J, Goncalves $L F$, et al. The role of inflammation and infection in preterm birth. Semin Reprod Med 2007;25:21-39.

6. Russell RB, Green NS, Steiner CA, et al. Cost of hospitalization for preterm and low birth weight infants in the United States. Pediatrics 2007;120:e1-e9.

7. Hagberg $\mathrm{H}$, Mallard $\mathrm{C}$, Jacobsson B. Role of cytokines in preterm labour and brain injury. BJOG 2005;112(Suppl 1):16-18.

8. Romero R, Gotsch F, Pineles B, et al. Inflammation in pregnancy: its roles in reproductive physiology, obstetrical complications, and fetal injury. Nutr Rev 2007:65:S194-S202.

9. Goldenberg RL, Hauth JC, Andrews WW. Intrauterine infection and preterm delivery. N Engl J Med 2000;342:1500-1507.

10. Yoon BH, Romero R, Kim M, et al. Clinical implications of detection of Ureaplasma urealyticum in the amniotic cavity with the polymerase chain reaction. Am J Obstet Gynecol 2000;183:1130-1137.

11. Berger A, Witt A, Haiden N, et al. Microbial invasion of the amniotic cavity at birth is associated with adverse short-term outcome of preterm infants. J Perinat Med 2003;31:115-121.

12. Galask RP, Varner MW, Petzold $C R$, et al. Bacterial attachment to the chorioamniotic membranes. Am J Obstet Gynecol 1984;148:915-928.

13. Romero R, Mazor M. Infection and preterm labor. Clin Obstet Gynecol 1988;31:553-584.
14. Goldenberg RL, Andrews WW, Hauth JC. Choriodecidual infection and preterm birth. Nutr Rev 2002;60:S19-S25.

15. Baergen RN. Manual of Benirschke and Kaufmann's pathology of the human placenta: Infectious Diseases. Springer: New York, 2005, pp 279-318.

16. Naeye RL, Ross S. Coitus and chorioamnionitis: a prospective study. Early Hum Dev 1982;6:91-97.

17. Pathology of the placenta. Infectious disorders of the placenta, 2 nd edn. Churchill Livingstone: Philadelphia, 1999, p 317-342.

18. Benirschuke K, Kaufmann P, Baergen R. Pathology of the human placenta: Infectious diseases. 5th edn. Springer: New York, 2006, pp 657-761.

19. Steel JH, Malatos $\mathrm{S}$, Kennea $\mathrm{N}$, et al. Bacteria and inflammatory cells in fetal membranes do not always cause preterm labor. Pediatr Res 2005;57:404-411.

20. Redline RW. Placental inflammation. Semin Neonatol 2004;9:265-274.

21. Redline RW. Inflammatory responses in the placenta and umbilical cord. Semin Fetal Neonatal Med 2006;11:296-301.

22. Redline RW, Faye-Petersen $\mathrm{O}$, Heller $\mathrm{D}$, et al. Amniotic infection syndrome: nosology and reproducibility of placental reaction patterns. Pediatr Dev Pathol 2003;6:435-448.

23. Goldenberg RL, Culhane JF, lams JD, et al. Epidemiology and causes of preterm birth. Lancet 2008:371:75-84.

24. Kempf VA, Trebesius K, Autenrieth IB. Fluorescent In situ hybridization allows rapid identification of microorganisms in blood cultures. J Clin Microbiol 2000;38:830-838.

25. Hogardt M, Trebesius K, Geiger AM, et al. Specific and rapid detection by fluorescent in situ hybridization of bacteria in clinical samples obtained from cystic fibrosis patients. J Clin Microbiol 2000;38: 818-825.

26. Espy MJ, Uhl JR, Sloan LM, et al. Real-time PCR in clinical microbiology: applications for routine laboratory testing. Clin Microbiol Rev 2006;19:165-256.

27. Bottari B, Ercolini D, Gatti M, et al. Application of FISH technology for microbiological analysis: current state and prospects. Appl Microbiol Biotechnol 2006;73:485-494.

28. Fredricks DN, Fiedler TL, Marrazzo JM. Molecular identification of bacteria associated with bacterial vaginosis. $\mathrm{N}$ Engl J Med 2005:353:1899-1911.

29. Melo AC, Almeida AM, Leal NC. Retrospective study of a plague outbreak by multiplex-PCR. Lett Appl Microbiol 2003;37:361-364.

30. Amann RI, Binder BJ, Olson RJ, et al. Combination of $16 \mathrm{~S}$ rRNA-targeted oligonucleotide probes with flow cytometry for analyzing mixed microbial populations. Appl Environ Microbiol 1990;56:1919-1925.

31. Nadkarni MA, Martin FE, Jacques NA, et al. Determination of bacterial load by real-time PCR using a broad-range (universal) probe and primers set. Microbiology 2002;148:257-266.

32. Holt JG, Krieg NR, Sneath PHA, et al. Bergey's Manual of Determinative Bacteriology. Williams \& Wilkins: Baltimore, 1994.

33. Yi J, Yoon B, Kim E. Detection and biovar discrimination of Ureaplasma urealyticum by real-time PCR. Mol Cell Probes 2005;19:255-260.

34. Mygind T, Zeuthen Sogaard I, Melkova R, et al. Cloning, sequencing and variability analysis of the gap gene from Mycoplasma hominis. FEMS Microbiol Lett 2000;183:15-21.

35. Eckmann L, Kagnoff MF. Intestinal mucosal responses to microbial infection. Springer Semin Immunopathol 2005;27:181-196.

36. Boulos L, Prevost M, Barbeau B, et al. LIVE/DEAD BacLight : application of a new rapid staining method for direct enumeration of viable and total bacteria in drinking water. J Microbiol Methods 1999;37:77-86.

37. Berney $M$, Hammes $F$, Bosshard F, et al. Assessment and interpretation of bacterial viability by using the LIVE/DEAD BacLight Kit in combination with flow cytometry. Appl Environ Microbiol 2007;73: 3283-3290. 
38. Corless CE, Guiver M, Borrow $\mathrm{R}$, et al. Contamination and sensitivity issues with a real-time universal 16S rRNA PCR. J Clin Microbiol 2000;38:1747-1752.

39. Harris KA, Hartley JC. Development of broad-range 165 rDNA PCR for use in the routine diagnostic clinical microbiology service. J Med Microbiol 2003;52:685-691.

40. Blattner FR, Plunkett III G, Bloch CA, et al. The complete genome sequence of Escherichia coli K-12. Science 1997;277:1453-1474.

41. Uphoff CC, Drexler HG. Detection of mycoplasma in leukemialymphoma cell lines using polymerase chain reaction. Leukemia 2002;16:289-293.

42. Garner CM, Hubbold LM, Chakraborti PR. Mycoplasma detection in cell cultures: a comparison of four methods. Br J Biomed Sci 2000;57:295-301.

43. Blanc W. Pathways of fetal and early neonatal infection. Viral placentitis, bacterial and fungal chorioamnionitis. J Pediatr 1961;59:473-496.

44. Rosen DA, Hooton TM, Stamm WE, et al. Detection of intracellular bacterial communities in human urinary tract infection. PLoS Med 2007;4:e329.

45. Ito $\mathrm{T}$, Kobayashi $\mathrm{D}$, Uchida $\mathrm{K}$, et al. Helicobacter pylori invades the gastric mucosa and translocates to the gastric lymph nodes. Lab Invest 2008;88:664-681.

46. van der Waaij LA, Harmsen HJ, Madjipour M, et al. Bacterial population analysis of human colon and terminal ileum biopsies with $16 \mathrm{~S}$ rRNAbased fluorescent probes: commensal bacteria live in suspension and have no direct contact with epithelial cells. Inflamm Bowel Dis 2005;11:865-871.

47. Bacterial infections in the fetus and newborn infant. Bacterial colonization, 2nd edn. WB Saunders Company: Philadelphia, PA, 1984, pp 55-76.

48. Seong HS, Lee SE, Kang JH, et al. The frequency of microbial invasion of the amniotic cavity and histologic chorioamnionitis in women at term with intact membranes in the presence or absence of labor. Am J Obstet Gynecol 2008;199:375.e1-375.e5.

49. Zervomanolakis I, Ott HW, Hadziomerovic D, et al. Physiology of upward transport in the human female genital tract. Ann NY Acad Sci 2007;1101:1-20.

50. Hein M, Valore EV, Helmig RB, et al. Antimicrobial factors in the cervical mucus plug. Am J Obstet Gynecol 2002;187:137-144.
51. Gyr TN, Malek A, Mathez-Loic F, et al. Permeation of human chorioamniotic membranes by Escherichia coli in vitro. Am J Obstet Gynecol 1994;170:223-227.

52. El Khwad M, Stetzer B, Moore RM, et al. Term human fetal membranes have a weak zone overlying the lower uterine pole and cervix before onset of labor. Biol Reprod 2005;72:720-726.

53. El Khwad M, Pandey V, Stetzer B, et al. Fetal membranes from term vaginal deliveries have a zone of weakness exhibiting characteristics of apoptosis and remodeling. J Soc Gynecol Investig 2006;13: 191-195.

54. Hutzal CE, Boyle EM, Kenyon SL, et al. Use of antibiotics for the treatment of preterm parturition and prevention of neonatal morbidity: a metaanalysis. Am J Obstet Gynecol 2008;199: 620-628.

55. Kenyon S, Pike K, Jones DR, et al. Childhood outcomes after prescription of antibiotics to pregnant women with spontaneous preterm labour: 7-year follow-up of the ORACLE II trial. Lancet 2008;372:1319-1327.

56. Kenyon S, Pike K, Jones DR, et al. Childhood outcomes after prescription of antibiotics to pregnant women with preterm rupture of the membranes: 7-year follow-up of the ORACLE I trial. Lancet 2008;372:1310-1318.

57. Romero R, Sibai B, Caritis S, et al. Antibiotic treatment of preterm labor with intact membranes: a multicenter, randomized, doubleblinded, placebo-controlled trial. Am J Obstet Gynecol 1993;169: 764-774.

58. Eschenbach DA, Nugent RP, Rao AV, et al. A randomized placebo-controlled trial of erythromycin for the treatment of Ureaplasma urealyticum to prevent premature delivery. The Vaginal Infections and Prematurity Study Group. Am J Obstet Gynecol 1991;164:734-742.

59. Klein LL, Gibbs RS. Use of microbial cultures and antibiotics in the prevention of infection-associated preterm birth. Am J Obstet Gynecol 2004;190:1493-1502.

60. McGregor JA, French Jl, Richter R, et al. Cervicovaginal microflora and pregnancy outcome: results of a double-blind, placebo-controlled trial of erythromycin treatment. Am J Obstet Gynecol 1990;163:1580-1591.

61. Lamont RF. Antibiotics for the prevention of preterm birth. N Engl J Med 2000;342:581-583. 